\title{
The Engineering Project Organization Society and megaprojects: literature analysis using keywords
}

DOI 10.2478/otmcj-2018-0015

Received May 09, 2018; accepted December 06, 2018

\begin{abstract}
The purpose of this paper is to analyze how the Engineering Project Organization Society (EPOS) has addressed the issue of megaprojects at their annual conferences organized from 2006 to 2016. The literature analysis used in this paper is a form of content analysis. It focuses on the usage of a particular term in scientific papers. In this case, the key term is "megaprojects" or "mega-projects". Papers in which this term appears are selected for further analysis. The findings show that the main keyword "megaproject" or "mega-project" appears 22 times in the identified papers. It appears in 10 titles and nine abstracts. Most important for this literature analysis, it appears in seven lists of keywords. Literature analysis proceeded by analyzing the associated keywords in the seven papers in which the main keyword "megaproject" or "mega-projects" can be found in the listed keywords. The analysis shows that the main associated keywords are "governance", "complexity", and "trust". This research provides a view of the collective understanding of megaprojects within the EPOS community and helps to shape further research in this field. In addition, the results of this research can be seen as a step forward for scholars and practitioners to discuss and develop a new theoretical framework for better understanding of megaproject governance.
\end{abstract}

Keywords: megaproject, governance, complexity, trust, Engineering Project Organization Society (EPOS)

\footnotetext{
*Corresponding author: Anita Ceric, Department of Construction Management and Economics, Faculty of Civil Engineering, University of Zagreb, Zagreb, Croatia; E-mail: anita@grad.hr Josip Sertic, Senior Adviser, Ernst \& Young, Advisory Croatia.
}

\section{Introduction}

The reason for addressing the megaproject topic in this paper is that Engineering Project Organization Society (EPOS) organized a joint meeting with the Fifth International Megaprojects Workshop at the EPOC annual conference in the US in 2017. On this special occasion, it is interesting to assess the major outputs from the research on megaprojects of the EPOS community. There are numerous research papers written over the past 2 decades about megaprojects. They focus on a wide range of topics, starting from different definitions of megaprojects (e.g., Flyvbjerg, 2003; Brooks and Locatelli, 2015), project planning and delivery (Lundrigan et al., 2015), risk management (Miller and Lessard, 2000; Flyvbjerg, 2003), and different case studies (Mahalingam, 2008; Ruuska et al., 2009; Chi et al., 2011), stakeholder management (Yang et al., 2014) to project complexity (Brockman and Girmsheid, 2007; Sertic, 2013) and project governance (Biesenthal and Wilden, 2014; Pelham and Duffield, 2016).

The most comprehensive literature analysis of megaprojects can be found in the paper written by $\mathrm{Hu}$ et al. (2015) and published in the Journal of Management in Engineering (American Society of Civil Engineers [ASCE]). It analyzed the major outputs of megaproject research published in top peer-reviewed journals, such as the International Journal of Project Management, the Journal of Construction Engineering and Management, Construction Management and Economics, Proceedings of the Institution of Civil Engineers - Civil Engineering, Leadership and Management in Engineering, and the Project Management Journal. Common keywords searched were "megaproject”, "mega project", "large project", "major project", and "complex project”. The topics of megaproject research identified by $\mathrm{Hu}$ et al. (2015) in 85 papers were organization and stakeholder management, project planning and procurement, cost and schedule management, construction and site management, risk analysis and management, IT innovation and utilization, leadership and professional development, complex project management, and project monitoring and control. 
This paper is organized in four sections. First, the research methodology is considered. This section focuses on the identification of papers published by EPOS researchers at annual conferences that contain the main keyword megaproject or mega projects. Second, the key findings are presented. In this section, a detailed analysis of the identified papers is presented. Moreover, it analyzes the associated keywords and their interconnection with the main keyword. Third, guidelines for further research are suggested. And fourth, conclusions and limitations of this research are offered.

\section{Research methodology}

The analysis of literature presented in this paper is based on the analysis by Ceric (2016) and proceeds in four distinct steps. First, the analysis started by identifying papers from the conferences organized by EPOS: Leadership and Management in Construction (LEAD) and Engineering Project Organization Conferences (EPOC). Second, for purposes of this literature analysis, the online archives of the LEAD and EPOC conferences held in the period from 2006 to 2016 were searched for the leading keyword "megaprojects" or "mega-projects" appearing anywhere in the papers. It should be noted here that keywords have become essential in literature search, the latter being the tool that nowadays guides the academic community in any field of research. This explains key role of keywords in literature analysis. Third, the identified papers were analyzed to identify the associated keywords listed by the authors. Only those papers with the leading keyword were selected for further analysis. Fourth, all keywords from the identified papers were analyzed for their interconnections, which thereby also suggest connections between different concepts.

Tab. 1: LEAD and EPOC papers published from 2006 to 2016.

\begin{tabular}{llc}
\hline Year & Conference & Papers \\
\hline 2006 & LEAD & 50 \\
2008 & LEAD & 15 \\
2009 & EPOC & 23 \\
2010 & EPOC & 37 \\
2011 & EPOC & 34 \\
2012 & EPOC & 50 \\
2013 & EPOC & 50 \\
2014 & EPOC & 38 \\
2015 & EPOC & 43 \\
2016 & EPOC & 45 \\
Total & & 385 \\
\hline
\end{tabular}

Table 1 shows all LEAD and EPOC papers listed by year. Altogether, there are 385 of them. The literature analysis presented in this paper covers only full papers that are available in the online EPOS archives. In cases where only abstracts are available, they were excluded from further analysis.

\section{Main findings}

The list of identified papers containing the main keyword "megaproject" or "mega-project" in the listed keywords, titles, abstracts, or anywhere within the text of the papers published from 2006 to 2016 is presented in Table A1. It should be noted that neither LEAD nor EPOC conference was held in 2007.

In the 385 papers published between 2006 and 2016, the main keyword "megaproject" or "mega-project" appeared seven times in the listed keywords, nine times in the titles, nine times in the abstracts, and 22 times anywhere in the text. Table 2 shows the incidence of the keyword "megaprojects" or "mega-projects" in the LEAD and EPOC conference proceedings.

Brockman (2009) published the first paper that contained the main keyword "megaproject" in the listed keywords. Two such papers were published in 2010 and 2016, with one paper published in 2011. In 2015, special attention was given to megaprojects, with a keynote paper presented by Gil (Lundrigan et al., 2015). Unfortunately, the keywords for this paper are not provided (Table A1). Furthermore, three of the above papers deal with case studies from China.

Table 3 shows all papers published from 2006 to 2016 with the main keyword "megaproject" or "mega-project." Here, all 22 papers are listed in four categories, depending on where the main keyword appears - namely, keywords, title, abstract, and anyplace else in the text.

Seven papers that contain the main keyword "megaproject" in the keywords listed by the authors were selected for further analysis. Other keywords from the identified papers were analyzed for their interconnections, which suggest connections between different concepts too.

Tab. 2: Incidence of the keyword "megaprojects" or "mega-projects" in LEAD and EPOC conferences.

\begin{tabular}{lcccc}
\hline Conference & Keywords & Title & Abstract & Text \\
\hline LEAD & 0 & 0 & 0 & 2 \\
EPOC & 7 & 9 & 9 & 20 \\
Total & 7 & 9 & 9 & 22 \\
\hline
\end{tabular}


Tab. 3: Papers cited containing the main keyword "megaprojects" or "mega-projects."

Keywords

Brockman (2009); Haidar and Ellis Jr. (2010); Li et al. (2010); Chi et al. (2011); Hu et al. (2012); Pelham and Duffield (2016); Zhai et al. (2016)

Title Brockman (2009); Haidar and Ellis Jr. (2010); Li et al. (2010); Ho and Lin (2010); Chi et al. (2011); Hu et al. (2012); Lundrigan et al. (2015); Pelham and Duffield (2016); Zhai et al. (2016)

Abstract Brockman (2009); Haidar and Ellis Jr. (2010); Li et al. (2010); Chi et al. (2011); Hu et al. (2012); Lessard et al. (2013); Chi et al. (2011); Lundrigan et al. (2015); Pelham and Duffield (2016); Zhai et al. (2016) Text Mulva (2006); Mahalingam (2008); Harty and Whyte (2008); Chan and Levitt (2009); Brockman (2009); Davies et al. (2010); Haidar and Ellis Jr. (2010); Li et al. (2010); Ho and Lin (2010); Chi et al. (2011); Levitt (2011); Hu et al. (2012); Feng et al. (2013); Lessard et al. (2013); Edkins and Zerjav (2014); Awuzie and McDermott (2014); Collins et al. (2015); Lundrigan et al. (2015); Pelham and Duffield (2016); Zhai et al. (2016); Morris (2016); Edkins and Smith (2016)

The analysis shows that the most important associated keywords in the seven selected papers are "relational governance" (twice), "project governance" (once), "corporate governance" (once), "complexity" (twice), and "trust" (once). In addition, the associated keywords "governance" and "trust" appear together in one list of keywords. Figure 1 shows the interconnections between these associated keywords and the main keyword "megaproject”.

The associated keywords listed by the authors in the 22 selected papers that contain the keyword "megaproject" or "mega-project" anywhere in the text are as follows: "infrastructure" (four times), "public-private partnership" (twice), "project complexity” (once), "complexity framework” (once), "complexity” (four times), "project management" (four times), "project governance" (once), "corporate governance" (once), "relational governance" (twice), "stakeholder" (once), "trust” (once), and "culture" (twice).

Megaprojects are defined as temporary projects characterized by large investment and complexity (Brooks and Locatelli, 2015). Often enough, they are therefore described as large and complex projects. In a comprehensive analysis of the literature, $\mathrm{Hu}$ et al. (2015) also searched for these common keywords associated with megaprojects. Therefore, the online archive spanning the period 2006-2016 was searched once again for the common keywords connected to megaprojects, such as "large project" and "complex project". The analysis shows

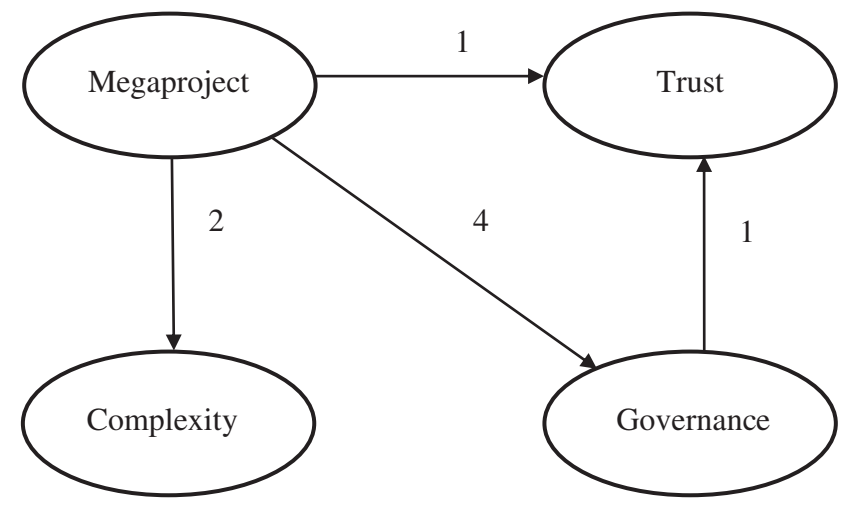

Fig. 1: Interconnections of the associated keywords in the seven selected papers with the main keyword "megaproject".

that of the 385 papers published in the period 2006-2016 at LEAD and EPOC annually conferences, only 17 papers contain the phrase "large and complex" anywhere in the text, 87 papers contain common keywords connected to megaprojects such as "large", and 70 papers contain the term "complex".

Keeping in mind that the term "megaproject" was introduced to the construction management field about 20 years ago, it can be concluded that results from the analysis presented herein do not show evidence that the EPOS community uses the term "megaproject" as the common term for large and complex projects. It can be expected that this will change in the future. Lately, megaprojects are attracting increasing attention from the research community in many fields, including project management and governance.

\section{Suggestions for further research}

Several directions for further research on the megaproject topic have been suggested in the previous section. They are based on the literature analysis of the EPOS community papers, as well as several papers published in peerreviewed journals. Special attention has been given to defining guidelines for further research in the EPOS Vision Paper (Arditi et al., 2014), wherein 10 leading thinkers in the field of Engineering Project Organization (EPO) were asked to share the Vison Statement of Grand Challenges for research and practice in EPO. The analysis presented in the main findings section shows that governance, complexity, and trust are the main keywords associated with the keyword "megaproject". However, their interconnections have not been studied sufficiently. Further research 
should focus on governance, complexity, and trust, as well as their interrelations.

\section{Governance}

Project governance supports an organization in aligning its project objectives with its organizational strategies, achieving set project activities, and monitoring performance (Biesenthal and Wilden, 2014). Governance is a multilevel phenomenon that facilitates interactions between organizational actors within and across organizational levels. It is important to note that trust plays a critical role in governance literature regarding managing the relationships between various actors. For instance, the term "relational governance" is often described as a form of governance in which arrangements based on trust complement complex contracts (Poppo and Zenger, 2002).

Megaprojects are usually undertaken by international construction joint ventures (ICJVs) that comprise at least two parties, which implies that their organization is more complex than the organization of a single contractor or a client (Brockman and Girmscheid, 2007). As the number of project parties grows, the number of contractual relationships between them grows linearly, while the number of noncontractual relationships grows exponentially. This is shown by the following two equations, respectively:

$$
\begin{gathered}
y=4 x-2 \\
y=2 x^{2}-2 x+2
\end{gathered}
$$

Therefore, the gap between contractual and noncontractual relationships between stakeholders becomes ever larger, as shown by the shaded area in Figure 2. That gap,

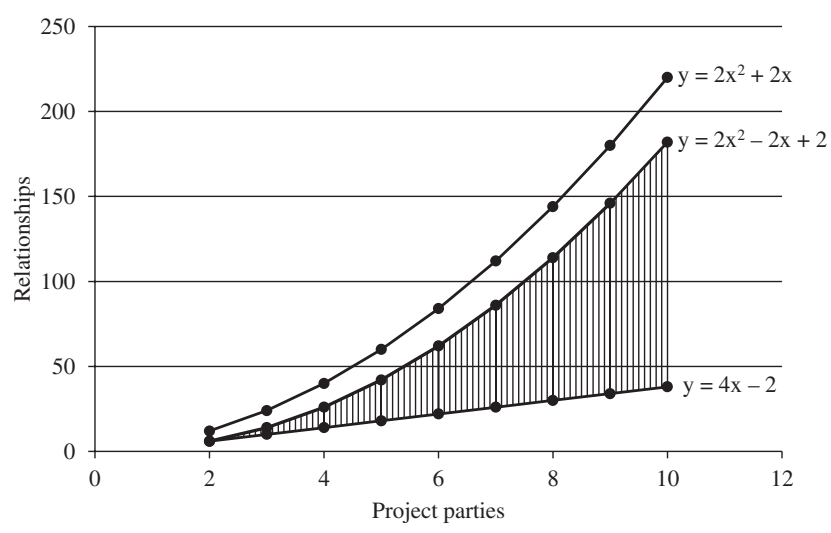

Fig. 2: Project parties and relationships with up to 10 parties (shaded area represents the noncontractual gap) (Ceric, 2016:107). however, cannot be closed by additional contracts. This makes trust between all project parties ever more important as projects grow. In very large and complex projects, often called megaprojects, the role of trust is consequently paramount (Ceric, 2016; Zhai et al., 2016).

\section{Complexity}

There has been growing academic interest in how complexity affects the management of megaprojects. Some of the authors have suggested that increasing complexity in projects could be a significant factor in project failure (Lessard and Miller, 2001; Flyvbjerg, 2003). Furthermore, complex projects are subject to high levels of uncertainty.

Project complexity is discussed in the literature in many different ways, but a simple definition relevant to project organization is still lacking. One way to address this problem is to define project complexity in terms of the network of project parties engaged. In network analysis, a useful measure is that of network connectivity. The so-called gamma index of network connectivity is a ratio between the actual number of links $(e)$ and the potential number of links given the number of nodes $(v)$ in a network. It varies between zero and one (Rodrigue et al., 2009:31). Simply put, the higher the gamma index, the greater is the project complexity from an organizational perspective. Moreover, network analysis provides many other measures of this nature, such as indexes of centrality and density. This definition would be useful in the context of governance, which has been discussed earlier.

The network of project parties is directly related to project governance. The parties include all stakeholders in a project. The more complex a project, the more complex is its governance structure. As shown in the following sections, such projects also require greater levels of trust between all the stakeholders.

\section{Trust}

Stakeholders play an important role in defining organizational strategy and change over time. According to Schlihter and Rose (2013), trust in an implementation project cannot be absolute or permanent but will vary dynamically over time and between stakeholders. Companies are now beginning to engage with stakeholders at a much earlier stage of a project than in the past. This is especially true for larger and more complex or controversial projects, where companies are initiating engagement at the very early prefeasibility or preexploration phases, signaling to communities and 
other local stakeholders that their views and well-being are considered important (International Finance Corporation, 2007). Stakeholders have their own objectives, interests, and expectations, which may conflict and cause challenges to project management (Yang et al., 2014).

A conceptual model of dynamics of trust among stakeholders over time is shown in Figure 3. Point A is a little above zero at the beginning. As the project goes forward, trust gradually increases as stakeholders become better acquainted with one another. However, a major conflict midway to project completion can lead to the breakdown of trust. As the decrease of trust between points B and C shows, it can be rather sharp. It is essential to stop the fall into distrust as soon as possible, as well as to establish a new point of departure for all stakeholders. This is depicted by the section of a circle between points $C$ and $D$. Having returned to "normal", stakeholders do their best to develop trust once again, thus returning to a trustful relationship by project completion. Major conflict between stakeholders can lead to a rapid decline of trust and thus represents a major risk in every project. Once in the distrust territory, stakeholders need to make an effort to develop trust once more. Distrust endangers project completion, pushing it forward in time. This is where communication between all stakeholders is of central importance.

\section{Governance, complexity, and trust}

As the above guidelines show, concepts of governance, complexity, and trust are deeply interrelated in connection with megaprojects. Future research needs to focus on these relations in the context of megaprojects. However, other concepts also play important roles in this connection. In particular, globalization and multiculturalism are of growing importance in this connection (Arditi et al.,

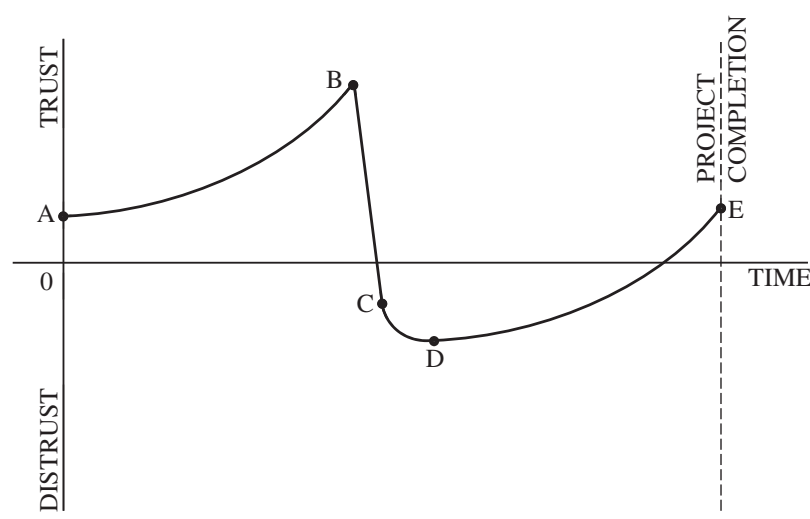

Fig. 3: Dynamics of trust among stakeholders (Ceric, 2016:15).
2014). This is especially true of megaprojects involving stakeholders from a number of countries, which may also belong to different cultural backgrounds.

The seven papers that have "megaprojects" or "mega-projects" among their keywords are of special interest in connection with the connections between the above concepts. For instance, Brockman (2009) deals with links between complexity and trust. Pelham and Duffield (2016) deal with the links between governance and complexity. Moreover, Zhai et al. (2016) deal with links between governance and trust. Therefore, links between all three concepts in the context of megaprojects offer many useful pointers for future research in this field.

\section{Conclusions}

The literature analysis has shown that a relatively small number of papers presented at LEAD and EPOC conferences have mentioned megaprojects explicitly. In particular, only 22 out of 385 papers mention megaprojects, and only seven papers contain this term among the keywords. As has been argued above, keywords play an essential part in literature search, which is essential in academic research. The analysis has shown that the interaction between the keyword "megaproject" or "mega-project" and the associated keywords offers useful information. In particular, the keywords "governance", "complexity", and "trust" are shown to be interrelated. The guidelines for future research have therefore focused on these keywords and their interaction.

It should be mentioned in this context that only 17 out of 385 papers refer to "large and complex" projects, which could be understood as the main characteristics of megaprojects. However, 87 papers refer to "large" projects, whereas 70 of them refer to "complex" ones. Given the growing importance of megaprojects in both research and practice, it would be useful for this term to appear more often in the literature. Moreover, this would increase the visibility of EPOS community research.

As the guidelines presented above suggest, the interplay among governance, complexity, and trust needs to be explored in future research. As has been shown, these concepts are deeply interrelated. In terms of future research, it would also be useful to explore megaprojects in line with the ideas provided in the EPOS Vision Paper (Arditi et al., 2014). In this context, globalization and multiculturalism are likely to play important roles in connection with megaprojects. Indeed, megaprojects increasingly often cross both national and cultural boundaries. This trend is likely to become ever more pervasive in the future. 


\section{References}

Arditi, D., Bell, L., Gann, D., Hughes, W., Lessard, D., Levitt, R., et al. (2014). Grand challenges in engineering project organization: EPOS vision statements, Working Paper Series. In: Taylor, J. T., Chinowsky, P. \& Sakhrani, V. (eds.), Proceedings of the Engineering Project Organization Conference, Winter Park, CO, July 29-31.

Awuzie, B. O., \& McDermott, P. (2014). Evaluating the impact of national culture on viability within infrastructure delivery systems, Working Paper Series. In: Taylor, J. T., Chinowsky, P., \& Sakhrani, V. (eds.), Proceedings of the Engineering Project Organization Conference, Winter Park, CO, July 29-31.

Biesenthal, C., \& Wilden, R. (2014). Multi-level project governance: Trends and opportunities. International Journal of Project Management, 32, pp. 1291-1308.

Brockman, C. (2009). Mega-Projects: Getting the Job Done. In: Proceedings LEAD Conference, South Lake Tahoe, CA.

Brockman, C., \& Girmsheid, G. (2007). Complexity of Megaprojects. In: Milford, R. (ed.), Proceedings of CIB World Building Congress: Construction for Development, South Africa, May 14-17, pp. 219-230.

Brooks, N. J., \& Locatelli, G. (2015). Power plants as megaprojects: Using empirics to shape policy, planning, and construction management. Utility Policy, 36, pp. 57-66.

Ceric, A. (2016). Trust in Construction Projects. Routledge, Abingdon, Oxon, and New York.

Chan, H., \& Levitt, R. (2009). Strategic and cultural drivers of renegotiation approaches in infrastructure concession agreements. In: Proceedings LEAD Conference, South Lake Tahoe, CA.

Chi, C. S. F., Ruuska, I., Levitt, R., Ahola, T., \& Artto, K. (2011). A relational governance approach for megaprojects: Case studies of Beijing 3 and Bird's Nest Projects in China, Working Paper Series. In: Proceedings of the Engineering Project Organization Conference, Estes Park, CO, August 9-12.

Collins W., Parrish K., \& Gibson G. E. (2015). Improving project performance within industrial focused organizations with the project definition rating index for small industrial projects, Working Paper Series. In: Dossik, C., \& Macht, G. (eds.), Proceedings of the Engineering Project Organization Conference, The University of Edinburgh, Scotland, UK, June 24-26.

Davies, A., Frederiksen, L., \& Dewulf, G. (2010). Business models, infrastructure and the changing public-private interface, Working Paper Series. In: Taylor, J., \& Chinowsky, P. (eds.), Proceedings of the Engineering Project Organization Conference, South Lake Tahoe, CA, November 4-6.

Edkins, A., \& Zerjav, V. (2014). A policy program on infrastructure interdependencies: Implications for front-end project management and opportunities for research, Working Paper Series. In: Taylor, J. T., Chinowsky, P., \& Sakhrani, V. (eds.), Proceedings of the Engineering Project Organization Conference, Winter Park, CO, July 29-31.

Edkins, A., \& Smith, A. (2016). The challenge of managing modern complex projects, Working Paper Series. In: Kaminsky, J., \& Zerjav, V. (eds.), Proceedings of the Engineering Project Organization Conference, Cle Elum, WA, June 28-30.
Feng, W., Lessard, D., Cameron, B. G., \& Crawely, E. F. (2013). Stakeholders, issues, and the shaping of large engineering projects, Working Paper Series. In: Proceedings of the Engineering Project Organization Conference, Winter Park, CO, July 9-11.

Flyvbjerg, B. (2003). Megaprojects and Risk: An Anatomy of Ambition. Cambridge University Press, Cambridge.

Haidar, A., \& Ellis, R. D. (2010). Analysis and improvement of megaprojects performance, Working Paper Series. In: Taylor, J., \& Chinowsky, P. (eds.), Proceedings of the Engineering Project Organization Conference, South Lake Tahoe, CA, November 4-6.

Harty, C., \& Whyte, J. (2008). The role of media in construction design work and ecologies of practice. In: Proceedings LEAD Conference, South Lake Tahoe, CA.

Ho, S. P., \& Lin, Y.-C. (2010). A model for the internationalization process of construction firms: A dynamic OLI view, Working Paper Series. In: Taylor, J., \& Chinowsky, P. (eds.), Proceedings of the Engineering Project Organization Conference, South Lake Tahoe, CA, November 4-6.

Hu, Y., Chan, A., \& Le, Y. (2012). Conceptual framework of program organization for managing construction megaprojects Chinese client's perspective, Working Paper Series. In: Proceedings of the Engineering Project Organization Conference, Rheden, The Netherlands, July 10-12.

Hu, Y., Chan, A. P. C., Le, Y. \& Jin, R.-Z. (2015). From construction megaproject management to complex project management: Bibliographic analysis. Journal of Management in Engineering, 31(4). pp. 04014052-1-04014052-11.

International Finance Corporation: World Bank Group. (2007). Stakeholder Engagement: A Good Practice Handbook for Companies Doing Business in Emerging Markets. IFC, Washington D. C., USA.

Levitt, R. E. (2011). Toward Project Management 2.0, Working Paper Series. In: Proceedings of the Engineering Project Organization Conference, Estes Park, CO, August 9-12.

Lessard, D. R., \& Miller, R. (2001). Understanding and managing risks in large engineering projects, MIT Sloan Working Paper No. 4214-01.

Lessard, D., Sakhrani, V., \& Miller, R. (2013). House of project complexity - understanding complexity in large infrastructure projects, Working Paper Series. In: Proceedings of the Engineering Project Organization Conference, Winter Park, CO, July 9-11.

Li, K., Wang, J., Zheng, Y., Wang, L., Orr, R., \& Jua, Y.-K. (2010). A hybrid decision support system for efficient planning and management of mega projects, Working Paper Series. In: Taylor, J., \& Chinowsky, P. (eds.), Proceedings of the Engineering Project Organization Conference, South Lake Tahoe, CA, November 4-6.

Lundrigan, L. Gil, N., \& Puranam, P. (2015). Why mega-projects (seem to?) fail: A meta-organizational perspective, Working Paper Series. In: Dossik, C., \& Macht, G. (eds.), Proceedings of the Engineering Project Organization Conference, The University of Edinburgh, Scotland, UK, June 24-26.

Mahalingam, A. (2008). PPP experiences in Indian States: Bottlenecks, enablers and key issues. In: Proceedings LEAD Conference, South Lake Tahoe, CA. 
Miller, R., \& Lessard, D. (2000). The Strategic Management of Large Engineering Projects: Shaping Institutions, Risks, and Governance. The MIT Press, Cambridge, MA.

Morris, P. (2016). Hinkley point C: The rhetoric and the reality: Risk and the management of nuclear power projects, Working Paper Series. In: Kaminsky, J., \& Zerjav, V. (eds.), Proceedings of the Engineering Project Organization Conference, Cle Elum, WA, June 28-30.

Mulva, P. S. (2006). Uncovering "hidden" project benefits through program management. In: Songer, A., Chinowsky, P., \& Carillo, P. (eds.), Proceedings of the 2nd Specialty Conference on Leadership and Management in Construction, Grand Bahama Island, Bahamas, May 4-6.

Pelham, N., \& Duffield, C. (2016). Mega-project governance - a case study of the governance of a successfully delivered project, Working Paper Series. In: Kaminsky, J., \& Zerjav, V. (eds.), Proceedings of the Engineering Project Organization Conference, Cle Elum, WA, June 28-30.

Poppo, L., \& Zenger, T. (2002). Do formal contracts and relational governance function as substitute or complements? Strategic Management Journal, 23, pp. 707-725.
Rodrigue, J.-P., Comtois, C., \& Slack, B. (2009). The Geography of Transport Systems, 2nd edn. Routledge, New York.

Ruuska, I., Artto, K., \& Lehtonen, P. (2009). Dimensions of distance in a project network: Exploring Olkiluoto 3 nuclear power plant. International Journal of Project Management, 27(2), pp. 142-153.

Sertic, J. (2013). Complexity in Construction Industry - Theoretical Baseline for Complexity Assessment in Construction Industry, Report submitted to EU COST Research Project "Mega-project" for Short Term Scientific Mission.

Schlihter, B. R., \& Rose, J. (2013). Trust dynamics in a large system implementation: Six theoretical propositions. European Journal of Information System, 32, pp. 455-477.

Yang, R., Wang, Y., \& Jin, X.-H. (2014). Stakeholders' attributes, behaviours, and decision strategies in construction projects: Importance and correlations in practice. Project Management Journal, 45(3), pp. 74-90.

Zhai, K. Z., Chi, C. S. F., \& Le, Y. (2016). Relational governance in megaprojects: From the owner's view, Working Paper Series. In: Kaminsky, J., \& Zerjav, V. (eds.), Proceedings of the Engineering Project Organization Conference, Cle Elum, WA, June 28-30.

\section{Appendix}

Tab. A1: Identified papers with the main keyword "megaproject" or "mega-project" in the period from 2006 to 2016

\begin{tabular}{|c|c|c|c|c|c|}
\hline Paper number & Keywords & Title & Abstract & Text & Associated keywords \\
\hline $2006-1$ & 0 & 0 & 0 & 1 & Keywords are not provided \\
\hline $2008-1$ & 0 & 0 & 0 & 1 & India, Infrastructure, Private-Public Partnerships, Bottlenecks, Strategies \\
\hline $2008-2$ & 0 & 0 & 0 & 1 & Keywords are not provided \\
\hline $2009-1$ & 0 & & 0 & 1 & Renegotiation, Arbitration, Public-Private Partnership, Culture \\
\hline $2009-2$ & 1 & 1 & 1 & 1 & Mega-Project, Complexity, Success Factors, Cognitive Maps \\
\hline $2010-1$ & 0 & 0 & 0 & 1 & Keywords are not provided \\
\hline 2010-2 & 1 & 1 & 1 & 1 & $\begin{array}{l}\text { Megaproject, Decision Support System, Project Appraisal, Genetic Algorithms, Hybrid } \\
\text { Approach }\end{array}$ \\
\hline 2010-3 & 1 & 1 & 1 & 1 & Megaprojects, Size \& Complexity, Performance, Integration \\
\hline $2010-4$ & 0 & 1 & 0 & 1 & Globalization, Internationalization, OLI Paradigm, Uppsala Model, Strategy \\
\hline 2011-1 & 1 & 1 & 1 & 1 & $\begin{array}{l}\text { Relational Governance, Megaprojects, China, Beijing Airport Terminal 3, Beijing } \\
\text { National Stadium, Bird's Nest }\end{array}$ \\
\hline 2011-2 & 0 & 0 & 0 & 1 & $\begin{array}{l}\text { Agile Management, Agile Software Development, Agility, Command-and-Control, } \\
\text { Decentralization, Discipline, Governance, Human Resources Management, Lean } \\
\text { Management, Power to the Edge, Project Management, Project Enterprise, Project } \\
\text { Management Body of Knowledge, Participative Management, Responsiveness, Small } \\
\text { Group Dynamics, Web 2.0. }\end{array}$ \\
\hline $2012-1$ & 1 & 1 & 1 & 1 & Program Organization, Construction Megaprojects, Client Organizations, China \\
\hline 2013-1 & 0 & 0 & 0 & 1 & Project Management, Stakeholder, Issue, Value Exchange, Network Analysis \\
\hline $2013-2$ & 0 & 0 & 1 & 1 & Projects, Complexity, Infrastructure, Project Architecture, Project Shaping, Risks \\
\hline 2014-1 & 0 & 0 & 0 & 1 & Infrastructure, Interdependencies, Management of Projects, Project Front End \\
\hline 2014-2 & 0 & 0 & 0 & 1 & National Culture, Viability, Infrastructure Delivery Systems \\
\hline 2015-1 & 0 & 0 & 0 & 1 & Front-End Planning, Industrial Construction, Small Projects, Complexity \\
\hline $2015-2$ & 0 & 1 & 1 & 1 & Keywords are not provided (Keynote) \\
\hline 2016-1 & 1 & 1 & 1 & 1 & Project Governance, Corporate Governance, Mega Project \\
\hline $2016-2$ & 1 & 1 & 1 & 1 & Relational Governance, Political Intervention, Trust, Megaprojects, China \\
\hline $2016-3$ & 0 & 0 & 0 & 1 & Keywords are not provided \\
\hline 2016-4 & 0 & 0 & 0 & 1 & Management of Projects, Project Complexity, Complexity Framework \\
\hline Total & 7 & 9 & 9 & 22 & \\
\hline
\end{tabular}

